\title{
A DINÂMICA DE LEGITIMAÇÃO NAS ORGANIZAÇÕES JORNALÍSTICAS: ESTUDO DE CASO GAZETA DO POVO
}

\author{
Ana Paula Mira ${ }^{1}$
}

\section{Resumo}

Esta pesquisa tem como objetivo estudar a dinâmica de legitimimação em organizações da mídia, especialmente no jornal Gazeta do Povo, do Estado do Paraná, no Brasil. Nosso objetivo é mostrar como a Gazeta do Povo enfrentou pressões institucionais ao longo de sua história como uma empresa. O principal objetivo desta pesquisa foi identificar esse processo, para analisar as pressões sobre o ambiente da organização e para entender a resposta da empresa para esses problemas, além de procurar entender como se deu a dinâmica de legitimação. Na realização desta pesquisa, foram utilizados métodos qualitativos.

Palavras-chave: Comunicação, administração, organização, ambiente institucional, Gazeta do Povo.

\begin{abstract}
This research aims at studying the dynamics of legitimation in media organizations, especially in the newspaper Gazeta do Povo, from the State of Paraná, in Brazil. Our goal is to show how Gazeta do Povo faced institutional pressures throughout its history as a company. The main objective of this research was to identify this process, to analyze the pressures on the organization's environment and to understand the company's response to those problems and how the dynamics of legitimation were held. In order to do this research, we used qualitative methods. Keywords: Communication, administration, organization, institutional environment, Gazeta do Povo.
\end{abstract}

\section{Introdução}

A questão da legitimidade organizacional tem sido estudada, especialmente a partir da década de 60. Suchman (1995, p. 574) conceitua a legitimidade como "uma percepção generalizada ou suposição de que as ações de uma entidade são desejáveis, apropriadas, adequadas ou de acordo com algum sistema socialmente construído de normas, valores, crenças e definições". A maior contribuição do autor foi ter exposto a dicotomia existente nessa busca da legitimidade, a partir de mecanismos de avaliação ou cognitivos. A legitimidade, dessa forma, pode ser considerada um recurso manipulável ou algo já estabelecido dentro de um sistema de crenças e valores. Para ele, ter consciência

\footnotetext{
${ }^{1}$ Jornalista (UFPR), mestre em Administração (Universidade Positivo), professora da Universidade Positivo, atuando na área de Comunicação.
} 
desses dois mecanismos é a forma mais eficiente de buscar, manter ou reparar a legitimidade organizacional.

Em ambos os casos, a ênfase está na agência, ou seja, na ação individual. Em particular, o foco recai sobre os quadros de gestão, na tentativa de persuadir o público com um discreto controle apoiado por recursos materiais e simbólicos (GOLANT; SILLINCE, 2007). Isso porque há uma relação bastante óbvia entre públicos e organizações: bens e serviços são oferecidos pelas empresas e pagos pelos consumidores. "Há outras relações que são menos óbvias, mas não menos importantes para sobrevivência organizacional. Uma delas envolve o desenvolvimento de legitimidade organizacional” (MASSEY, 2001, p. 153). De uma forma geral, portanto, as organizações precisam ser legítimas perante seus diferentes públicos, mesmo que isso se estabeleça por meio de normas, regulações morais ou cognitivas, como propôs Suchman (1995). Assim, todas as organizações possuem uma dinâmica própria de legitimação, cuja compreensão é essencial para entender o ato de legitimar-se.

Apesar de ser um tema bastante recorrente, especialmente se levar em consideração a visão institucional das organizações, são poucos os estudos concentrados especificamente nas organizações jornalísticas. Estas oferecem um "produto" bastante peculiar, a informação. Por conta disso, têm uma lógica, se não diferente, meritória de atenção. As organizações jornalísticas, por dependerem exclusivamente da dinâmica das sociedades, também apresentam uma dinâmica bastante particular de legitimação. Esse problema teórico pode ser identificado em textos do campo jornalístico, que têm abordado, por exemplo, crises na imprensa e formas de controle, o que abrange, em função disso, temas como o da legitimidade.

A discussão recente, por exemplo, a respeito de instrumentos que avaliem a disseminação da informação, como os Conselhos de Comunicação, é uma evidência de como a tentativa de fiscalização do serviço prestado pela mídia causa polêmica, mesmo que essa fiscalização possa ser benéfica para a imagem da organização e, consequentemente, para sua dinâmica de legitimação. Afinal, como organizações que são, os veículos de comunicação, constantemente sujeitos a avaliação, devem cada vez mais se preocupar com a legitimidade perante seus públicos. "[...] os editores insistem no seu direito de monitorar as atividades governamentais, empresariais e da sociedade em geral. 
Mas a grande maioria deles continua reagindo negativamente à ideia de ter alguém monitorando o que eles fazem" (ALMEIDA in DINES; VOGT; MELLO, 1997, p. 55).

É nesse ponto que o presente artigo se focou. Assim como outras organizações, as jornalísticas também precisam dispor de ferramentas que legitimem sua existência e suas atitudes. Quando a organização em questão é um veículo de comunicação, é primordial não apenas conquistar essa legitimação, como também mantê-la ou repará-la, caso seja necessário. No campo jornalístico, muitas vezes é citada a questão da credibilidade, ponto-chave para a própria discussão sobre legitimidade.

Empresas jornalísticas se estruturam, historicamente, também como negócios. Credibilidade informativa é um dos valores centrais e reafirmado em todos os cantos do planeta. A possível perda dela pode levar para um túnel sem saída uma atividade com fundamental papel na construção e manutenção da democracia: o Jornalismo (KARAM, 2010, s/p.).

Como será exposto ao longo do artigo, as organizações jornalísticas têm sido questionadas recorrentemente em relação a sua atuação na sociedade. Massey (2001, p. 153) diz que "quando confrontadas com uma crise, as organizações são obrigadas a se comunicar estrategicamente com os públicos de interesse para gerenciar sua legitimidade". Em termos organizacionais, o conceito de crise está relacionado de alguma forma à questão da legitimidade. "Uma crise é um evento importante e imprevisível, que ameaça prejudicar a organização e seus stakeholders" (MASSEY, 2001, p. 157).

No entanto, é possível perceber que nem sempre os momentos de crise são os mais significativos para a dinâmica de legitimação de uma organização. No caso a ser pesquisado, do jornal Gazeta do Povo, foi possível perceber que vários eventos ou períodos foram importantes para essa dinâmica, mesmo não sendo considerados períodos turbulentos ou decisivos sob o ponto de vista do ambiente institucional. Porém, são apontados como igualmente importantes para a conquista, manutenção ou reparação de legitimidade, a partir das respostas estratégicas dadas a esse mesmo ambiente.

\section{Legitimidade organizacional e ambiente}

$\mathrm{Na}$ visão moderna de organizações como sistemas abertos, o tema que tem merecido atenção por parte de pesquisadores é a legitimidade organizacional. Vistas inicialmente como sistemas fechados, as organizações passaram a ser consideradas sistemas abertos. Dessa forma, levam-se em conta normas culturais, símbolos, crenças e 
rituais de uma determinada sociedade (SUCHMAN, 1995). É a partir dessa visão que surge a ideia de legitimidade, porém, de forma bastante frágil. Muitos autores citam o termo, mas poucos o conceituam em sua totalidade.

John Dowling e Jeffrey Pfeffer (1975) relacionam a questão da legitimidade ao comportamento organizacional. Eles defendem o conceito de que a legitimidade é a congruência entre valores e normas da empresa com os valores da sociedade em que estão inseridas, e sua falta ameaça a legitimidade de uma organização, tanto legal, quanto econômica e socialmente. Os autores, dessa forma, retomam o que outros já escreveram sobre o tema, como Parsons (1956), Emery e Trist (1965) e Udy (1970) (apud Dowling e Pfeffer, 1975), sobre o fato de as organizações refletirem um ambiente socialmente construído e, portanto, necessitarem desenvolver estratégias que as legitimem perante a sociedade em que estão inseridas.

Zelditch (2001) também pontuou aspectos da legitimidade - "o problema mais antigo da história das sociedades" - que tornam o conceito bastante plural, dependendo do ponto de vista. Para o autor, a diferença das visões começou com os próprios gregos, que verificaram em obras distintas (de Platão e de Aristóteles, especialmente) a usabilidade da legitimidade, mas não sua explicação. Mais além, cita-se a mudança dessa visão, que passa a considerar a legitimidade como um estabilizador informal da ordem social. "A estabilidade de uma estrutura emergente é um dos problemas a serem resolvidos por alguma teoria de processo, e a legitimidade é o fator de estabilidade de muitas dessas estruturas" (ZELDITCH, 2001, p. 4).

Ao falar sobre organizações e legitimidade, é imprescindível estabelecer critérios de análise para entender seu papel na sociedade. Um deles diz respeito ao ambiente. Por muito tempo, considerou-se que o ambiente era o único a influenciar as organizações, sem que ocorresse o contrário.

Crubellate e Machado-da-Silva (1998) chamam atenção para o ambiente como algo teoricamente construído e que tem como consequência diferentes noções apoiadas em pressupostos diferentes. O primeiro deles relaciona o ambiente a fatos objetivos, aos quais se pode ter acesso, e que podem ser descritos, definidos e explicados pelos membros de uma organização. O segundo "não se refere a qualquer contexto tangível ou objetivo, mas simplesmente envolve influências contextuais assim definidas pelos indivíduos que atuam na organização" (CRUBELLATE; MACHADO-DA-SILVA, 1998, p. 40). Com 
uma definição ampliada com base nos dois primeiros pressupostos, o terceiro pressuposto afirma que o ambiente é visualizado como um conjunto de fenômenos objetivos, mas que podem ser interpretados de maneira subjetiva pelos membros organizacionais. Considerando a perspectiva institucional como a que melhor se enquadra para esta pesquisa, a informação está sujeita a diversos aspectos políticos, econômicos e sociais que surgem no ambiente e suas interpretações.

Scott (2001) aborda a questão do ambiente institucional. Segundo ele, estudos passados enfatizavam os efeitos do contexto institucional em todas as organizações inseridas em um determinado ambiente, visto como único e que impunha estruturas ou práticas às quais a organização deveria se adaptar. O ambiente, sob essa perspectiva, já estava dado, imposto. Apenas em pesquisas mais recentes começou-se a considerar diferenças entre as organizações, reconhecendo, inclusive, se, quando e como respondem ao ambiente. Scott (2001) argumenta que essa resposta pode variar.

\footnotetext{
Algumas vezes, as organizações respondem com estratégias, outras com mudanças estruturais ou se defendendo de pressões. Às vezes, as demandas são negociadas coletivamente atentando ao que se estabelece como fundamental para as instituições e redefinindo ambientes. (SCOTT, 2001, p. 149)
}

Ao considerar a relação entre ambiente e organizações, Meyer a Rowan (1977) consideram que organizações são estruturadas por fenômenos ambientais e tendem a se tornar isomórficas, ideia ampliada alguns anos depois por DiMaggio e Powell (1983), que definiram mecanismos pelos quais a organização poderia sofrer pressões isomórficas. $O$ isomorfismo parte do princípio de que as organizações respondem de maneira semelhante a outras que já estejam mais adaptadas ao ambiente em que estão inseridas.

Para entender esses conceitos, é importante ressaltar, aqui, a diferença entre ambiente técnico e institucional, já que pressões isomórficas surgem nesse contexto.

O ambiente técnico caracteriza-se pela troca de bens e serviços, em que o critério de avaliação é a eficiência organizacional; já o ambiente institucional refere-se a regras e a procedimentos necessários à legitimidade organizacional em face de exigências sociais. (CRUBELLATE; MACHADO-DA-SILVA, 1998, p. 40) 
Outro conceito, apontado por Machado-da-Silva e Fernandes (1998), tão importante quanto a diferença entre os ambientes, é o que eles chamam de contexto institucional de referência.

(...) ambientes técnicos e institucionais podem ser visualizados em diversos níveis de análise: local, regional, nacional e internacional. Cada organização, diante da necessidade de definir estratégias de ação, orienta-se pelo contexto institucional no nível que mais se coaduna com sua trajetória e, portanto, com sua lógica interior. (MACHADO-DA-SILVA; FERNANDES, 1998, p. 49)

Para os autores, além de ser necessário considerar os ambientes técnico e institucional, é imprescindível entender que existe o contexto de referência, já que este é dinâmico e pode ser o fator de sucesso ou de fracasso das estratégias de legitimação utilizadas pela organização.

Muitas organizações trabalham de forma equivocada seu relacionamento com o ambiente, quer pela compreensão estreita do que constitui o ambiente, quer pela definição do que vem a ser seu contexto institucional de referência. (MACHADO-DA-SILVA; FERNANDES, 1998, p. 49)

No ambiente institucional, portanto, é que se estabelecem de maneira mais evidente as pressões institucionais, já que os ambientes técnicos têm como característica "o controle ambiental exercido sobre os resultados em termos de quantidade e qualidade de bens" (idem, p. 49). A partir dessa perspectiva, as organizações procuram atuar de maneira isomórfica a fim de garantir sua legitimidade.

Meyer e Rowan (1977) apontam algumas consequências para as instituições que atuam dessa maneira em um ambiente institucional. A primeira delas é a incorporação de elementos que são legitimados externamente, e não a partir de critérios de eficiência. A segunda é a organização empregar critérios de avaliação externa ou cerimoniais para definir o valor de seus elementos estruturais. A terceira e última consequência é a dependência de instituições externas para reduzir turbulências e manter a estabilidade. Dessa forma, o isomorfismo - responsável pela homogeneização das instituições - pode ser competitivo e institucional. O competitivo é evidente em campos organizacionais com competição livre e aberta; já o institucional abrange organizações que lutam por poder político e que procuram legitimidade institucional. Este último deu origem ao que 
DiMaggio e Powell (1983) chamam de mecanismos pelos quais ocorrem as mudanças isomórficas institucionais: isomorfismo coercitivo, mimético e normativo.

O isomorfismo coercitivo "resulta de pressões externas formais e informais vindas de outras organizações das quais uma organização é dependente e por expectativas culturais vindas da sociedade nas quais a organização exerce alguma função” (DI MAGGIO; POWELL, 1983, p. 67). A resposta às pressões isomórficas a partir desse mecanismo pode ser uma mudança estrutural ou até mesmo com caráter cerimonial, apesar de não ser inconsequente. Todas as respostas vêm da coerção, das regras e da autoridade impostas por determinadas demandas do ambiente.

O segundo mecanismo é o isomorfismo mimético, que está centrado na imitação de estratégias que já deram certo em outras organizações. Esse modelo pode ser copiado a partir de estudo de empresas especializadas em determinar a melhor maneira de se comportar naquele ambiente como também pode ser copiado de maneira não intencional, já que vários modelos atravessam décadas como exemplos a serem seguidos no que tange à condução de uma organização (DI MAGGIO; POWELL, 1983).

O isomorfismo normativo é o terceiro mecanismo para as organizações buscarem a homogeneidade. Relaciona-se à profissionalização, especialmente, já que abrange quadros de profissionais e maneiras de se adequarem ao que o ambiente impõe.

Todos os três mecanismos estão atrelados à perspectiva institucional, já que vão além de considerar o ambiente fator preponderante para a atuação de organizações também se consideram as respostas que essa organização vai dar a esse mesmo ambiente. Por conta disso, é essencial entender a relação entre ambiente e legitimidade; sobre esta, outra importante contribuição de Zelditch (2001) é a classificação da legitimidade em teorias que apontam para uma lógica do consenso e aquelas que pendem para a ideia de conflito.

Meyer e Rowan (1977) foram um pouco mais além e relacionaram a estrutura formal das organizações à institucionalização, ou seja, à existência de regras e normas em um ambiente claramente influenciado pelas relações internas e externas das organizações. Thompson (apud Dowling e Pfeffer, 1975) também evidenciou que a legitimação ocorre no nível institucional e em organizações formais.

Como a questão da legitimidade é, hoje, primordial para as empresas modernas, o questionamento comum é como ela pode ser acessada/conquistada. Suchman (1995) 
aponta três fatores que, segundo ele, regem essa questão: o ganho, a manutenção e a reparação dessa legitimidade. Segundo Suchman (1995), em algum momento a organização passa por uma dessas três fases (quando não concomitantemente). Para Terrebery (apud Dowling e Pfeffer, 1975), a legitimidade é mediada pela troca de recursos. Porém, não há legitimação apenas com alocação adequada de recursos, assim como o inverso também não é verdadeiro.

Se a legitimidade não pode ser acessada apenas por uma competição por recursos econômicos, ela também não se pauta apenas no que é legal ou ilegal. Em regimes democráticos, essas leis variam, mudam e se adaptam. Há três motivos para isso acontecer: acontece uma mudança natural das leis que acabam alterando também o que é considerado legítimo; as normas podem ser - e são - contraditórias; é possível tolerar certos comportamentos informalmente, mas sem dar sanção legal a eles (DOWLING e PFEFER, 1975).

Dessa forma, cabe descrever três comportamentos organizacionais a partir dessas afirmações: há ações que são economicamente viáveis; ações que são simplesmente legais ou ainda aquelas que são legitimadoras. Como consequência direta, está a importância de normas e valores, visíveis na comunicação de uma cultura e que também se refletem na comunicação da própria sociedade. Essas normas e valores não são imutáveis, o que possibilita dizer que acabam também forçando mudanças nas organizações; esse sistema é, inclusive, uma fonte de pressão para a legitimidade organizacional. Neste ponto, Dowling e Pfeffer (1975) mostram que, a partir do momento que a sobrevivência organizacional é reforçada pela legitimidade, esta pode ser vista como um recurso.

Um ponto importante - e um diferencial dos autores Dowling e Pfeffer (1975) - é o fato de verem a legitimidade organizacional como uma restrição para as empresas, como um "mal necessário". Para Perrow (apud Dowling e Pfeffer, 1975), as organizações, para se tornarem legítimas, podem adaptar sua produção, objetivos, métodos de operação para entrar em conformidade com as definições de legitimidade; podem, também, alterar a definição de legitimidade, conforme suas práticas de produção; ainda podem tentar, por meio da comunicação, adequar-se a valores e normas seguidas por organizações já legitimadas. A legitimidade, dessa forma, envolve mudança na missão da organização ou no uso de símbolos para identificar organizações com instituições sociais ou práticas legitimadas. 
Em conformidade com essa ideia, Suchman (1995) considera que a legitimidade opera de maneiras distintas em diferentes contextos. Para conquistá-la, leva-se em consideração a congruência entre os valores de uma organização e o ambiente cultural em que está inserida. Apesar de vários autores já terem definido a legitimidade (DOWLING \& PFEFFER, 1975; DiMAGGIO \& POWELL, 1983), Suchman (1995) adota uma definição em que se consideram dimensões avaliativas e cognitivas no processo da legitimação. Golant e Sillince (2007, p. 1150) explicam: “a dimensão cognitiva da legitimidade refere-se à maneira pela qual a ação coletiva é um resultado com base no entendimento comum, ao invés de uma avaliação de meios e fins". Dessa forma, papel importante desempenha a audiência coletiva quando se aborda a legitimidade organizacional, já que ela só pode ser construída socialmente a partir da coletividade.

Em suma, quando se diz que um certo padrão de comportamento possui legitimidade, afirma-se que um grupo de observadores, como um todo, aceita ou suporta o que os observadores consideram ser o comportamento padrão como um todo - apesar das reservas que qualquer observador isolado pode ter sobre qualquer comportamento único. (SUCHMAN, 1995, p. 574. Tradução livre.)

A legitimidade afeta não só a maneira como o público vê a organização, mas também como age em relação a ela. Uma organização é legítima quando é vista não apenas como mais digna, mas também como mais significativa, mais previsível e mais confiável, o que define os propósitos da busca pela legitimidade: a criação e/ou manutenção da audiência (SUCHMAN, 1995). Para conquistar essas audiências, a legitimidade pode passar por dois diferentes processos: estratégico e institucional. $\mathrm{Na}$ visão estratégica, a legitimação é percebida como recurso operacional; ela é proposital e calculada. Já na institucional, ela é considerada uma ferramenta para constituir crenças e valores, cujas influências dos ambientes externo e interno são igualmente importantes.

Estudiosos têm se centrado nas explicações do agente da organização centrado na legitimação, o que favorece a sua dimensão avaliativa, ou em explicações estruturais, nas quais se destacam as pressões isomórficas impostas às organizações individualmente para se tornarem e permanecerem legítimas para as partes interessadas. (MASSEY, 2001, p. 153)

Cabe, aqui, ressaltar que, nessa dicotomia, se considerarmos a linha institucional de estudo das organizações, atenta-se para o argumento de Scott (2001), particularmente 
quando ele delimita os três pilares institucionais - regulador, normativo e cognitivocultural. A perspectiva institucional em questão contempla aspectos simbólicos que até então eram ignorados. Dentre esses três elementos, sempre há um que predomina dependendo da natureza da instituição, no entanto, há uma combinação permanente entre eles, mesmo que operem por meio de diferentes mecanismos.

Outra questão acerca da legitimidade diz respeito à sua finalidade. Para DiMaggio e Powell (1983), a organização procura tornar-se legítima a fim de usar sua legitimidade para reforçar o seu apoio e garantir a sua sobrevivência. As organizações que omitem elementos ambientalmente legitimados de estrutura ou criam estruturas únicas podem ser consideradas não legítimas. Tais organizações são mais vulneráveis a alegações de que elas são negligentes, irracionais ou desnecessárias. Reivindicações dessa natureza, sejam elas feitas por participantes internos, constituintes externos ou o governo, podem incorrer em custos reais para a organização.

DiMaggio e Powell (1983) também abordam a questão da busca de legitimidade a partir de critérios externos de valor. Esses critérios incluem, por exemplo, premiações, endossos por pessoas importantes, contratação de profissionais e consultores ou o prestígio de programas adotados pela organização. Nesse ponto, inclusive, é possível também remeter a Dowling e Pfeffer (1975), que, ao relacionarem legitimidade e comportamento, explicitam dois comportamentos legitimadores: contribuições a partir de caridade, pois há benefícios econômicos, especialmente em relação a impostos, relacionando a empresa a um comportamento altruísta e ainda determinando um comportamento fácil de ser identificado; e a cooptação, quando a empresa busca líderes políticos ou outras pessoas com legitimidade para o seu Conselho.

Tudo isso coaduna com a ideia de Meyer e Rowan (1983) ao não ignorar a relação entre organizações e ambientes. Além disso, as restrições impostas por normas e valores sociais e as reações a essas restrições são importantes para analisar o comportamento de uma organização. Essa hipótese, inclusive, é uma potencial justificativa para o presente trabalho, já que leva em consideração a pesquisa empírica sobre legitimidade e ações de legitimação. Para essa análise, é fundamental ter uma abordagem que enfoque legitimidade como uma restrição ao comportamento organizacional. Ao passo que isso acontece, organizações, cujos valores, produção ou métodos operacionais são variáveis de acordo com as normas sociais e valores vigentes, tendem a alterar esses valores 
também. Para Mason (apud Dowling e Pfeffer, 1975), a responsabilidade das empresas modernas é identificar se os seus valores são congruentes com o que prevalece na sociedade como um todo.

A legitimidade é uma restrição para todas as organizações, mas ela afeta mais algumas do que outras. Primeiro porque algumas organizações são mais visíveis e segundo porque outras dependem de mais suporte social e político. Essas organizações tendem a investir muito mais em um comportamento legitimador.

Com base nisso, é possível perceber em Suchman (1995) o fenômeno da legitimidade do ponto de vista da conduta estratégica das organizações. Ao expor a dicotomia da legitimidade como recurso ou como algo já estabelecido, o autor sugere a fusão dessas duas visões, já que ora a legitimação pode ser considerada um recurso manipulável, ora o resultado de um sistema de crenças já estabelecidas.

\section{DESAFIOS DO GERENCIAMENTO DA LEGITIMIDADE}

Suchman (1995) propõe que as organizações gerenciem sua legitimidade. Para isso, é necessário passar pelo estágio inicial, de aquisição de legitimidade, para depois mantê-la ou, em alguns casos, repará-la. Outro ponto importante a ser ressaltado é a comunicação das organizações. "Como a maioria dos processos culturais, a gestão da legitimidade se assenta fortemente sobre a comunicação, neste caso, a comunicação entre a organização e os seus diversos públicos” (SUCHMAN, 1995, p 586). Para entender melhor o gerenciamento proposto pelo autor, é preciso conhecer os passos para aquisição, manutenção e reparação da legitimidade.

Aquisição de legitimidade

A abertura de uma nova organização sempre traz desafios e talvez o maior deles seja conquistar a confiança dos públicos. Adquirir credibilidade e garantir legitimidade são tarefas que os líderes organizacionais têm de cumprir quando uma nova organização entra no mercado. Para essa aquisição, há dois principais aspectos: quando novas operações são tecnicamente problemáticas ou mal institucionalizadas ou quando os setores são realmente novos. Algumas estratégias são propostas por Suchman (1995, p. 587. Tradução livre) para conquistar legitmidade. 


\begin{abstract}
As estratégias para conquistar legitimidade se dividem em três grupos: (a) os esforços para estar em conformidade com os ditames das audiências preexistentes dentro do ambiente atual da organização, (b) esforços para selecionar, nos vários ambientes, uma audiência que apoiará as práticas atuais, e (c) os esforços para manipular o ambiente estrutural através da criação de novos públicos e novas crenças de legitimação. Os três grupos envolvem misturas complexas de organização, mudança organizacional e comunicação persuasiva.
\end{abstract}

Os gestores organizacionais, muitas vezes, procuram conquistar legitimidade a partir de organizações já preexistentes, conforme o ambiente. O caminho pode ser procurar o que já deu certo naquele segmento de mercado e seguir a mesma linha para conquistar os públicos. Normalmente, as ações variam de acordo com a legitimidade desejada: pragmática, moral ou cognitiva. Para conquistar a pragmática conforme o ambiente, basta se adequar ao que o público quer, por meio de ações de marketing que deem resultados mais rápidos, porém menos duradouros. A legitimidade moral exige que o processo seja mais concreto, adequando-se a valores e crenças de um público que só será convencido a partir de resultados permanentes. Como visto anteriormente, a legitimidade cognitiva é a mais difícil de ser conquistada e esta, devido a essa condição, passa a ser consequência da conquista das legitimidades pragmática e moral.

Se as organizações obtêm legitimidade pragmática, por meio de demandas instrumentais, e legitimidade moral, por meio de ideais altruístas, ganham legitimidade cognitiva, principalmente, ao estabelecer modelos ou padrões. Ao longo destas linhas, os institucionalistas salientam que organizações em ambientes incertos, muitas vezes, buscam aceitação em crenças naturalizadas e inquestionáveis por meio de isomorfismo mimético, ou seja, imitando as entidades mais importantes e seguras em seus campos. (SUCHMAN, 1995, p. 589. Tradução livre)

Se a intenção dos gestores não for a conformidade com o ambiente, uma outra estratégia é selecionar os ambientes desejados. Nessa perspectiva, também deve-se levar em consideração a legitimidade desejada, já que cada uma exige ações diferentes. A legitimidade pragmática exige uma pesquisa de mercado para que os gestores saibam detectar ações diferenciadas. Para a moral, é preciso verificar valores e crenças para adaptá-las às atitudes da empresa de maneira diferenciada, porém sem mudanças estruturais profundas. Também pode ser exercida uma seleção em ambientes cognitivos, mas é um pouco mais raro devido à dificuldade de manipulação desse tipo de legitimidade. 
No entanto, as estratégias de ganho de legitimidade podem não ser suficientes se os gestores optarem apenas pela conformidade ou seleção. Nesse caso, é necessária a manipulação de ambientes, que consiste na intervenção no ambiente em que a organização se insere.

Neste caso, os gestores devem ir além da simples escolha entre as crenças existentes culturais, mas devem propagar ativamente novas explicações da realidade social. Tal manipulação dinâmica cultural é menos controlável, menos comum, e, consequentemente, muito menos entendida que qualquer seleção ou conformidade de ambiente (SUCHMAN, 1995, p. 591. Tradução livre).

A legitmidade pragmática, nesse caso, é conquistada com publicidade de produtos e relações de troca. Para passar à moral, é um desafio maior, já que exige bons resultados permanentemente. A legitimidade cognitiva, consequentemente, depende de uma ação coletiva, como investimento em estratégias de comunicação e convencimento de novas ideias em um ambiente no qual já há crenças e valores instituídos.

Manutenção de legitimidade

Pesquisadores sobre legitimidade afirmam que manter a legitimidade é mais fácil do que conquistar ou repará-la. No entanto, não é raro descuidar da manutenção. "Anomalias, equívocos, falhas de imitação, inovações e choques externos ameaçam a legitimidade da organização, mesmo as mais seguras, especialmente se tais infortúnios acontecem rápido ou permanecem inalterados durante um período significativo de tempo" (SUCHMAN, 1995, p. 594. Tradução livre).

Três aspectos, portanto, podem indicar problemas para manter a legitimidade: públicos frequentemente heterogêneos, estabilidade que leva à rigidez e a institucionalização que gera sua própria oposição. O primeiro deles, que se refere ao público, pode desestabilizar a organização se esta não estiver atenta às mudanças e não investir em constante inovação. A estabilidade pode parecer "um castelo de cartas", em uma metáfora de Jepperson (1991, apud Suchman, 1995). O terceiro item, que se refere à institucionalização, pode abranger audiências insatisfeitas com a mudança, ponto fraco para a concorrência no que diz respeito a membros menos institucionalizados, assim como precipitação de uma crise de legitimação. 
Para manter a legitimidade, então, há algumas estratégias, que se dividem em dois grupos: perceber mudanças futuras e proteger realizações passadas. Quando já se conquistou legitimidade, a organização precisa se preparar ainda mais para perceber mudanças nos públicos e prever determinadas reações. Isso implica monitorar o ambiente externo e não se iludir com a posição confortável já conquistada. Assim como ocorre quando se quer ganhar legitimidade, para mantê-la é preciso diferenciar qual delas interessa à organização.

Para perceber emergentes demandas pragmáticas, a organização deve monitorar vários interesses, e, para este efeito, pode cooptar públicos dentro da organização que tomem decisões e que forneçam informações aos gestores culturais. Para perceber crenças morais emergentes, a organização deve incorporar múltiplas éticas e, para este fim, podem obter profissionalização, cooptando certos membros da organização para participar de discursos normativos externos (DiMaggio \& Powell, 1983). Finalmente, para perceber emergentes aspectos cognitivos, a organização deve explorar perspectivas múltiplas, e, para isso, pode criar subunidades específicas como "ver para crer", com um mandato para questionar afirmações pré-estabelecidas. (Cf. Ashforth \& Gibbs, 1990; Mitroff \& Kilmann, 1984). (SUCHMAN, 1995, p. 595. Tradução livre.)

O segundo grupo de estratégias, de proteger ações já realizadas, exige da organização um cuidado mais apurado em relação a acontecimentos que possam destruir a legitimidade já conquistada. Para isso, deve policiar constantemente suas ações internas, evitar que estratégias de legitimidade se limitem a questões técnicas e desenvolver um arsenal defensivo dos apoios, crenças e valores defendidos por ela.

\section{Reparação de legitimidade}

Reparar legitimidade pode até se comparar a ganhar legitimidade, no que concerne à dificuldade estratégica. No entanto, a reparação normalmente aparece em uma situação de crise. Massey (2001) ressalta que as organizações estão enfrentando crises com cada vez mais frequência, dada a crescente sofisticação de bens e serviços, o aumento da dependência de tecnologia, além de outras complicações. Algumas estratégias são propostas por Suchman (1995) para reparar legitimidade organizacional. A maioria delas podem ser as mesmas utilizadas para ganhar ou manter legitimidade, no entanto, a reparação exige uma ruptura com os padrões estabelecidos e o início de uma nova maneira de pensar a relação com seus públicos. 
A comunicação é essencial nessa etapa, principalmente porque as estratégias passam por normalização de contas e reestruturação. Embora as crises de legitimidade normalmente aconteçam por questões de desempenho, elas trazem consigo a desconfiança das audiências em relação a tudo que é feito a partir da ruptura. Para Suchman (1995), os gestores podem tentar, primeiro, negar o problema para amenizar preocupações pragmáticas das audiências, pelo menos até que a organização possa oferecer alguma espécie de compensação. A menos que a negação seja sincera, isso pode prejudicar a organização a longo prazo e diminuir sua reserva de legitimidade. "Assim, ao invés de negar o problema, os gestores podem optar por desculpá-lo por questionar a responsabilidade moral da organização. Infelizmente, essa tática em segundo lugar, que muitas vezes equivale a culpar os funcionários individuais ou autoridades externas, também tem dois lados, porque sugere uma ausência de controle gerencial” (SUCHMAN, 1995, p. 598).

Porém, não basta negar ou oferecer desculpas, explicações e justificativas. A organização precisa, acima de tudo, reconfigurar sua base de legitimação e partir para um processo de reestruturação para que a reparação seja realmente eficiente.

\section{INSTITUIÇÕES E LEGITIMIDADE}

Nenhuma discussão sobre legitimidade está alheia à própria discussão sobre instituições. O conceito de instituição tem sofrido muitas mudanças nos últimos séculos, especialmente no século 20. Para entendê-la, nas décadas de 70 e 80 basicamente se olhava o ambiente em que ela estava inserida. Analisavam-se as pressões exercidas por ele - técnicas e institucionais - e, com base nisso, determinava-se o que era uma instituição. O conceito de Scott (2001, p. 49), resume a ideia: “Instituições são compostas por elementos normativos, cognitivos e culturais, que, associados a recursos, proporcionam estabilidade e significado à vida social".

Apenas a partir da década de 90 que se começa a dar importância para a pressão que as organizações também exercem sobre o ambiente. Uma das principais contribuições da teoria foi a inclusão do elemento cultural na sua perspectiva de análise, o que levou a considerar o ambiente como um fator importante para melhor e maior compreensão das organizações. 
Catalisadora desse processo, a teoria institucional (TI) buscou reagir aos modelos de organização baseados em concepções racionalistas e que consideravam as instituições sistemas fechados. Para a TI, as organizações são sistemas abertos, sujeitas à pressão do ambiente e capazes, em contrapartida, de influenciarem esse mesmo ambiente. Nessa perspectiva, incluíram-se conceitos antes não relacionados às organizações, como valores, crenças, ambiente e cultura.

Berger e Luckmann (2002), ao publicarem na década de 60 a Construção Social da Realidade, fizeram a importante ligação entre ambiente e o surgimento das instituições. Além dessa relação, também evidenciaram a relevância de processos como o da formação de hábitos, da linguagem e do conhecimento. Tudo isso está intimamente ligado à história das instituições.

Segundo os autores, ao contrário de outras espécies, o homem continua seu desenvolvimento já em contato com o ambiente. "O processo de tornar-se homem efetuase na correlação com o ambiente. (...) A direção de seu desenvolvimento é socialmente determinada" (BERGER; LUCKMANN, 2002, p. 71). Ao mesmo tempo, ele tem contato com os ambientes natural e humano, o que lhe impõe uma interação com elementos além dos biológicos. O "eu" do ser humano, dessa forma, está correlacionado a esses dois ambientes e lhe confere uma possibilidade única de construção da sua realidade. "O organismo e, ainda mais, o eu não podem ser devidamente compreendidos fora do particular contexto social em que foram formados" (idem, 2002, p. 74).

A ordem social, dessa maneira, é um produto da própria atividade humana, na qual se formam os hábitos, com a essencial função de evitar ter que escolher entre muitas opções para uma dada situação, mesmo que esta ocorra novamente. "A formação do hábito da atividade humana é coextensiva com a institucionalização desta última" (BERGER; LUCKMANN, 2002, p.79).

A partir desse pensamento, tem-se a ideia de instituição, calcada em três pilares: tipificações partilhadas de ações habituais, historicidade e controle. As instituições, portanto, não se criam de um momento para outro; elas têm uma história, sem a qual é impossível compreender a instituição como um todo. Essa história, construída pelo partilhamento de hábitos, também impõe o controle da conduta humana, que aqui não deve ser confundido com os mecanismos específicos de sanções dentro de uma sociedade. 
"O controle social primário é dado pela existência de uma instituição enquanto tal" (BERGER; LUCKMANN, p. 80).

A visão de instituição de Berger e Luckmann, em 1967, foi crucial para o desenvolvimento da teoria institucional. Por isso, também está presente na obra de outros autores. Segundo Rossoni (2006), Selznick (1948) foi também um importante autor para esse processo, já que na visão deste a organização pode ser afetada tanto pelas características sociais de seus participantes como pelas próprias variáveis surgidas no ambiente. Outro autor, Zucker (1987) (apud Rossoni, 2006, p. 35), evidencia duas abordagens teóricas para a teoria institucional: a primeira vê o ambiente como instituição e a segunda considera a organização como instituição.

Dado esse pensamento, era essencial começar a pensar as organizações de forma diferente. Oliver (1992) foi uma importante pesquisadora que considerou as organizações como instituições ativas, não mais passivas em relação ao ambiente.

\section{PRESSÕES INSTITUCIONAIS}

Como visto anteriormente, compreender a diferença entre ambiente técnico e institucional é imprescindível para abordar o que são pressões institucionais. Para Meyer e Rowan (1977, p. 342),

(...) muitas das posições, políticas, programas e procedimentos de organizações modernas são aplicados pela opinião pública, pelos pontos de vista dos componentes importantes, pelo conhecimento legitimado pelo sistema educacional, pelo prestígio social, pelas leis e pelas definições de negligência e prudência utilizadas pelos tribunais. Tais elementos da estrutura formal são manifestações de regras institucionais poderosas que funcionam como mitos altamente racionalizados que são obrigatórios para organizações.

Dessa forma, perceber as pressões e saber como interpretá-las é essencial para as organizações formularem suas respostas estratégicas bem como suas formas de legitimação. Costumam, dessa forma, adaptar seus contextos institucionais, mas muitas vezes desempenham um papel ativo na construção desse contexto. Ou seja, as pressões podem ser externas, mas também surgirão da própria dinâmica de mudança das próprias organizações. 
Isso fica muito evidente no presente estudo de caso desta dissertação, já que a Gazeta do Povo atuou também como peça fundamental para moldar o ambiente em que se inseriu, o que, inclusive, acontece até hoje. Para Meyer a Rowan (1977, p. 348), “a incorporação de elementos institucionalizados fornece uma conta de suas atividades que protege a organização de ter sua conduta questionada". No mesmo texto, os autores indicam que o sucesso organizacional depende dessa coordenação entre fatores produtivos, atividades e ambiente. "Em parte, isso depende de processos ambientais e da capacidade de uma dad liderança organizacional para moldar esses processos" (idem).

\section{RESPOSTAS ESTRATÉGICAS}

Na perspectiva institucional, já delimitada neste trabalho, não só se leva em consideração o ambiente em que as organizações estão inseridas como também as respostas que elas podem dar às pressões institucionais exercidas por esse mesmo ambiente. Oliver (1991) e Sá (2009) explicam o conceito e propõem diferentes tipos de resposta estratégica às pressões institucionais.

Em 1991, Christine Oliver lançou luz aos estudos organizacionais ao perceber as organizações como ativas em relação ao ambiente. Para ela, há uma forte influência do contexto que as cerca. A autora inicia sua explanação fazendo uma comparação entre a perspectiva institucional (PI) e a de dependência de recursos (PDR). Em ambas, as organizações estão sujeitas a múltiplas pressões externas, vivem em ambientes coletivos e interconectados e dependem da capacidade de resposta a expectativas e demandas externas para sua sobrevivência. Os motivos para o comportamento organizacional também são convergentes nas duas teorias: as organizações procuram estabilidade, legitimidade e são dirigidas por interesses.

No entanto, Oliver (1991) aponta divergências entre as duas perspectivas, que vão determinar as respostas estratégicas dadas pelas organizações a diferentes situações. A diferença começa pela própria visão de ambiente, um institucional e outro de tarefas. $\mathrm{Na}$ perspectiva institucional, o comportamento é da não escolha, há uma conformidade com normas coletivas e crenças, além de as pressões serem invisíveis. Na perspectiva de dependência de recursos, há a possibilidade da escolha, relação de interdependência com as normas e pressões visíveis. Outras diferenças referem-se à maneira como manipulam o ambiente. Na PI, acontece o isomorfismo e há uma aderência às regras e às normas, ao 
contrário da PDR, na qual há uma adaptação ao ambiente e gerenciamento de escassos recursos. Para Oliver (1991, p. 148), “essas diferenças, por sua vez, levam a conclusões alternativas sobre respostas adequadas ao ambiente", por isso a importância de comparar as duas perspectivas para chegar a uma organização mais ativa e até mesmo capaz de manipular o ambiente que a cerca.

Com base nisso, a autora propõe cinco tipos de respostas estratégicas para os processos institucionais: aquiescer, comprometer-se, evitar, desafiar ou manipular. Antes da explanação de cada uma das respostas, é importante visualizar qual a tática para cada resposta estratégica, além de exemplos citados pela autora.

Quadro 1 - Respostas estratégicas para processos institucionais

\begin{tabular}{|l|l|l|}
\hline \multicolumn{1}{|c|}{ Resposta estratégica } & \multicolumn{1}{|c|}{ Táticas } & \multicolumn{1}{c|}{ Exemplos } \\
\hline \multirow{4}{*}{ Aquiescer } & Seguir hábito & Seguir normas invisíveis dadas como certas \\
\cline { 2 - 3 } & Imitar & Imitar modelos institucionais \\
\cline { 2 - 3 } & Acatar & Obedecer a regras e aceitar normas \\
\hline \multirow{4}{*}{ Negociar } & Equilibrar & Equilibrar as expectativas de vários públicos \\
\cline { 2 - 3 } & Pacificar & Apaziguar e acomodar elementos institucionais \\
\cline { 2 - 3 } & Barganhar & Negociar com públicos institucionais \\
\hline \multirow{4}{*}{ Desafiar } & Dissimular & Disfarçar não conformidade \\
\cline { 2 - 3 } & Amortecer & Relaxar relações institucionais \\
\cline { 2 - 3 } & Escapar & Mudar metas, atividades e domínios \\
\hline \multirow{5}{*}{ Manipular } & Dispensar & Ignorar normas e valores explícitos \\
\cline { 2 - 3 } & Desafiar & Contestar regras e exigências \\
\cline { 2 - 3 } & Atacar & Violar as fontes de pressões institucionais \\
\hline & Cooptar & Importar públicos influentes \\
\cline { 2 - 3 } & Influenciar & Moldar valores e critérios \\
\cline { 2 - 3 } & Controlar & Dominar processos e públicos institucionais \\
\hline
\end{tabular}

Fonte: adaptado de Christine Oliver (1991, p. 152)

\section{Métodos e técnicas}

A presente pesquisa é do tipo qualitativa, já que privilegia significados e interpretações, bem como processos de sua formulação e compartilhamento. Tem 
natureza descritiva, sob a perspectiva temporal retrospectiva, no nível de análise organizacional, e utilizou o método de estudo de caso, cujo objeto foi o jornal Gazeta do Povo. A escolha da Gazeta do Povo se deu pelo fato de ser o jornal mais antigo do Paraná ainda em circulação, além de sua tiragem ser a maior do Estado - em 2011, segundo IVC (Instituto Verificador de Circulação) a tiragem média diária foi de 45.000 exemplares, pelo menos 10 mil a mais do seu concorrente Folha de Londrina. Se considerarmos os jornais impressos apenas na cidade de Curitiba, a Gazeta concorre apenas com o Jornal do Estado, que tem tiragem diária de 10.500 exemplares.

Foram realizadas duas etapas de pesquisa. A primeira foi referente ao levantamento bibliográfico sobre os conceitos de ambiente, instituição, legitimidade e respostas estratégicas. Na segunda etapa, foi feita a pesquisa de campo, não só com análise dos documentos e relatórios que contam a história da Gazeta do Povo, como também com entrevistas semiestruturadas com funcionários do jornal. Foram oito entrevistas semiestruturadas, de 24 de janeiro a 8 de fevereiro de 2012, que tiveram um roteiro mínimo de perguntas, com o objetivo de apontar questões principais que poderiam ser desenvolvidas pelos entrevistados que foram:

Audrey Possebom, Editora-executiva de Vida Pública ${ }^{2}$ há três anos. Foi repórter e editora. Está na Gazeta do Povo há 12 anos. Identificado, nesta pesquisa, como Entrevistado 1.

Axeu Aislan Beluca, gerente de Marketing Jornais. Apesar de não fazer parte da redação, foi escolhido para apresentar as estratégias de marketing da Gazeta do Povo e como o departamento interage com a redação. Está à frente do departamento de Marketing da Gazeta do Povo há quatro anos. Identificado, nesta pesquisa, como Entrevistado 2.

* Eduardo Aguiar, Chefe de Redação há um ano. Trabalhou como editorexecutivo por oito anos e como editor por três anos, além de ter iniciado como repórter. Está na Gazeta do Povo há 14 anos. Identificado, nesta pesquisa, como Entrevistado 3.

* Guilherme Cunha Pereira, Vice-presidente. Filho de Francisco Cunha Pereira Filho, que assumiu a Gazeta do Povo na década de 60, Guilherme começou a trabalhar de

\footnotetext{
${ }^{2} \mathrm{Na}$ ocasião da entrevista, Audrey Possebom ainda era editora-executiva, mas foi promovida a Chefe de Redação na última semana de fevereiro de 2012, por isso seu nome no organograma está em uma posição diferente da apresentada na entrevista.
} 
forma ativa no jornal em 1998, quando do início da fase de transição da primeira para a segunda geração. Identificado, nesta pesquisa, como Entrevistado 4.

Maria Sandra Teixeira Gonçalves, Diretora de Redação há um ano. Trabalhou como repórter, editora de Internacional, editora-executiva, Chefe de Redação e editora de Opinião. Está na Gazeta do Povo há 14 anos. Identificado, nesta pesquisa, como Entrevistado 5.

Marisa Abrantes Boroni Valério, Editora-executiva de Economia há quatro anos. Foi editora antes da atual função. Está na Gazeta do Povo há 11 anos. Identificado, nesta pesquisa, como Entrevistado 6.

Nelson Souza Filho, Coordenador do Conselho Editorial. Atuou como repórter, editor, editor-executivo, chefe de redação e hoje faz parte também da editoria de Opinião. Está na Gazeta do Povo há 36 anos. Identificado, nesta pesquisa, como Entrevistado 7.

Roberto Massignan Filho, Editor de Automóveis. Iniciou como repórter policial e foi editor de outras áreas. Está na Gazeta do Povo há 36 anos. Identificado, nesta pesquisa, como Entrevistado 8.

A lógica da amostragem utilizada foi intencional, tendo em vista pessoas que conheciam a história da Gazeta do Povo e que também eram responsáveis por tomada de decisões dentro da organização. Além disso, alguns entrevistados também conheciam a fundo a estratégia da empresa em determinados momento de sua história.

O quadro abaixo mostra um resumo das respostas estratégicas que a Gazeta do Povo deu a diferentes tipos de pressão institucional.

Quadro 2 - Respostas estratégicas Gazeta do Povo.

\begin{tabular}{|c|c|c|c|c|c|c|}
\hline Característica & $\begin{array}{l}\text { Acontecimento/ } \\
\text { evento/ período }\end{array}$ & Data & $\begin{array}{c}\text { Pressão } \\
\text { institucional }\end{array}$ & $\begin{array}{l}\text { Tipo de resposta } \\
\text { estratégica }\end{array}$ & O que se fez & $\begin{array}{l}\text { Gerenciamento } \\
\text { da legitimidade }\end{array}$ \\
\hline A FUNDAÇÃOO & $\begin{array}{l}\text { Criação da Gazeta } \\
\text { do Povo por } \\
\text { Benjamin Lins e De } \\
\text { Plácido e Silva }\end{array}$ & 1919 & $\begin{array}{l}\text { No ambiente } \\
\text { institucional, a } \\
\text { Gazeta do Povo } \\
\text { surge como um } \\
\text { jornal que } \\
\text { pretende ser } \\
\text { diferente do } \\
\text { que já existe } \\
\text { em termos de }\end{array}$ & $\begin{array}{l}\text { Aquiescência } \\
\text { (seguir hábitos) }\end{array}$ & $\begin{array}{l}\text { A Gazeta do Povo é } \\
\text { criada e passa a noticiar } \\
\text { os fatos de Curitiba, sem } \\
\text { muita diferença em } \\
\text { relação ao que já se fazia } \\
\text { em outros jornais locais. }\end{array}$ & $\begin{array}{l}\text { Ganho de } \\
\text { legitimidade }\end{array}$ \\
\hline
\end{tabular}


DITO EFEITO - ISSN 1984-2376 - v. 6, n. 8, jan./jun. 2015 - UTFPR CURITIBA - http://periodicos.utfpr.edu.br/de

\begin{tabular}{|c|c|c|c|c|c|c|}
\hline & & & $\begin{array}{l}\text { veículos de } \\
\text { comunicação. }\end{array}$ & & & \\
\hline CONSOLIDAÇÃO & $\begin{array}{l}\text { Aquisição da Gazeta } \\
\text { do Povo por } \\
\text { Francisco Cunha } \\
\text { Pereira Filho e } \\
\text { Edmundo Lemanski }\end{array}$ & 1962 & $\begin{array}{l}\text { A Gazeta } \\
\text { precisa se } \\
\text { adequar ao fato } \\
\text { de que } \\
\text { veículos, de } \\
\text { uma maneira } \\
\text { geral, não } \\
\text { apresentavam } \\
\text { equilíbrio nas } \\
\text { finanças. }\end{array}$ & $\begin{array}{l}\text { Negociação } \\
\text { (equilíbrio) }\end{array}$ & $\begin{array}{l}\text { Buscou-se equilíbrio de } \\
\text { vários públicos, } \\
\text { principalmente por parte } \\
\text { de credores, já que o } \\
\text { jornal tinha muitas } \\
\text { dívidas nesse período. }\end{array}$ & $\begin{array}{l}\text { Manutenção de } \\
\text { legitimidade }\end{array}$ \\
\hline $\begin{array}{l}\text { MUDANÇAS } \\
\text { RADICAIS }\end{array}$ & $\begin{array}{l}\text { Contratação de } \\
\text { consultoria externa }\end{array}$ & $\begin{array}{l}1999 \\
\text { a } \\
2001\end{array}$ & $\begin{array}{l}\text { A Gazeta do } \\
\text { Povo } \\
\text { apresenta-se } \\
\text { como a } \\
\text { mudança } \\
\text { esperada pelos } \\
\text { constituintes da } \\
\text { organização, no } \\
\text { sentido de } \\
\text { oferecer } \\
\text { informação de } \\
\text { uma forma } \\
\text { mais moderna e } \\
\text { direta com seus } \\
\text { públicos. }\end{array}$ & $\begin{array}{l}\text { Aquiescência } \\
\text { (imitação) }\end{array}$ & $\begin{array}{l}\text { Contratou-se a } \\
\text { Consultoria da } \\
\text { Universidade de Navarra, } \\
\text { famosa por já ter } \\
\text { implantado seu processo } \\
\text { em outros jornais, o que } \\
\text { levou a GP a imitar } \\
\text { modelos institucionais }\end{array}$ & $\begin{array}{l}\text { Reparação de } \\
\text { Legitimidade }\end{array}$ \\
\hline $\begin{array}{l}\text { OPOSIÇÃO } \\
\text { INÉDITA }\end{array}$ & $\begin{array}{l}\text { Governo Roberto } \\
\text { Requião }\end{array}$ & $\begin{array}{l}2002 \\
\mathrm{a} \\
2006\end{array}$ & $\begin{array}{l}\text { No ambiente } \\
\text { institucional, } \\
\text { pressões } \\
\text { institucionais } \\
\text { de natureza } \\
\text { política surgem } \\
\text { no sentido de } \\
\text { exigir } \\
\text { posicionamento } \\
\text { do jornal. }\end{array}$ & $\begin{array}{l}\text { Desafio } \\
\text { (ataque) }\end{array}$ & $\begin{array}{l}\text { A GP passou a se } \\
\text { posicionar diante dos } \\
\text { ataques do ex-governador } \\
\text { ao jornal; essa foi a forma } \\
\text { de o jornal diferenciar-se } \\
\text { de outros veículos e de } \\
\text { sua própria imagem. }\end{array}$ & $\begin{array}{l}\text { Reparação de } \\
\text { legitimidade }\end{array}$ \\
\hline $\begin{array}{l}\text { UMA NOVA } \\
\text { IDENTIDADE }\end{array}$ & $\begin{array}{l}\text { Publicação da série } \\
\text { Diários Secretos }\end{array}$ & 2010 & $\begin{array}{l}\text { Pressão por } \\
\text { parte dos } \\
\text { leitores de } \\
\text { maior } \\
\text { transparência } \\
\text { no tratamento } \\
\text { dos assuntos de } \\
\text { natureza } \\
\text { pública. }\end{array}$ & $\begin{array}{l}\text { Desafio } \\
\text { (ataque) }\end{array}$ & $\begin{array}{l}\text { O jornal questionou e } \\
\text { investigou o poder } \\
\text { público em um momento } \\
\text { de muita interação com o } \\
\text { leitor e de amplo acesso à } \\
\text { informação; um ano } \\
\text { depois, a GP conquistou o } \\
\text { Prêmio Esso de } \\
\text { Jornalismo. }\end{array}$ & $\begin{array}{l}\text { Manutenção de } \\
\text { legitimidade }\end{array}$ \\
\hline
\end{tabular}

Fonte: Oliver (1991), Suchman (1995) e entrevistas semiestruturadas realizadas pela autora. 


\section{Conclusão}

Desde que se iniciaram as discussões sobre legitimidade nas organizações, considerou-se a influência dos ambientes institucionais sobre elas e sua recíproca, além do fato de que as organizações poderiam responder às pressões do ambiente. Oliver (1991), Scott (2001), Crubelatte (2004), entre outros autores, abordaram as respostas estratégicas possíveis para uma organização, dependendo das pressões, suas causas, ambientes, dentre tantas outras variáveis. A partir disso, foi possível estabelecer como cada organização procurou se legitimar e como se construiu essa dinâmica de legitimação.

De acordo com Oliver (1991), as respostas estratégicas que uma organização dá em relação às pressões ambientais podem ter objetivos diferentes de aquiescência, comprometimento, negação, desafio ou manipulação. Consideramos para a discussão essa classificação, a fim de poder determinar como foi a postura do jornal em períodos/eventos importantes para a história do veículo e como isso contribuiu para sua dinâmica de legitimação.

A dinâmica de legitimação da Gazeta do Povo passou por fases diversas e por variados tipos de respostas estratégicas diante das pressões do ambiente institucional. $\mathrm{Na}$ maior parte de sua existência, a Gazeta preferiu a aquiescência ou o desafio, respostas tão diversas quanto opostas quando se levam em consideração as suas consequências para a legitimação. Também foi possível verificar qual a intenção da Gazeta do Povo em cada período no que tange ao gerenciamento de sua legitimidade - se quis ganhar, manter ou repará-la. Considerando essas perspectivas, pode-se voltar essa discussão não só às respostas estratégicas que a organização deu ao ambiente diante de pressões institucionais, mas também aos tipos de legitimação pretendida e às estratégias de gerenciamento.

Desde seu início, em 1919, a Gazeta do Povo, assim como qualquer outra organização, procurou legitimar-se. Ela se inseria em um mercado já conhecido, dos veículos de comunicação impressos, porém ainda pouco explorado, especialmente no Paraná. Suas primeiras ações procuraram manter o que sua audiência já conhecia, o que a levou a conquistar legitimidade pragmática, ou seja, suficiente para o período de início e compatível com o que se esperava de um jornal. Naquele momento, a notícia ainda era mostrada de forma opinativa, assim como em outros veículos, e a Gazeta não mudou essa maneira de passar a informação. Suchman (1995) ressalta que a legitimidade pragmática 
é a mais fácil de ser conquistada, já que a organização apenas incorpora componentes em sua prática ou adota um comportamento já conhecido e aceito pelos seus públicos. Dessa forma, pode-se considerar que a resposta estratégica dada ao ambiente, de aquiescência seguindo e mantendo hábitos internalizados pelos públicos -, ajudou a Gazeta do Povo a firmar-se como um veículo impresso curitibano que, logo no final da década de 40, já era o jornal mais lido de Curitiba. O ambiente institucional de referência, importante conceito de Machado-da-Silva e Fernandes (1998) e que determina a visão do gestor diante da organização, era local, restrito à capital. O objetivo de aquisição de legitimidade foi facilmente atingido mesmo que a cobertura se limitasse à cidade, sem ampliá-la a todo o estado do Paraná.

No entanto, como em qualquer processo dinâmico - fato que ficou bastante evidente nesta pesquisa - as organizações devem também estar em constante mutação para sobreviverem e se manterem em suas áreas de atuação. A aquisição da Gazeta do Povo, em 1962, teve como objetivo redefinir algumas características conquistadas ao longo das décadas de 20, 30, 40 e 50. Em primeiro lugar, os novos donos já apresentavam um contexto de referência bastante diferente dos antigos proprietários. Cunha Pereira Filho e Lemanski não queriam mais restringir o jornal ao âmbito local e passaram a considerar a possibilidade de ampliar a linha editorial da Gazeta do Povo para uma visão mais regional. É nessa época que se iniciam campanhas que visavam ao desenvolvimento do estado e, como consequência, a manutenção da legitimidade adquirida nas décadas anteriores. Buscava-se agora legitimidade moral, essencialmente "sociotrópica", segundo Suchman (1995), e que depende mais do julgamento se a organização é certa ou errada a partir de determinados valores e princípios presentes na sociedade, do que da sua confirmação como uma organização que segue modelos compatíveis com outras na mesma área de atuação. Manter o que já havia sido conquistado era fundamental, porém, os novos donos queriam mais. O objetivo era a Gazeta do Povo ser vista como um jornal de princípios e atitude. Não à toa o jornal se empenhou, às vezes por anos, em campanhas em prol da população, como a dos royalties de Itaipu ou pelo melhor aparelhamento do Aeroporto Afonso Pena. Além da estratégia de mudar seu ambiente institucional de referência, também se alterou a resposta estratégica dada àquele novo contexto: a Gazeta passou a negociar com seus públicos, buscando seu equilíbrio, agradando àqueles que já confiavam no veículo bem como tentando "arrebanhar novos fiéis". Houve na mesma 
época, junto com o equilíbrio, a barganha com os públicos que lhe interessavam diretamente para atingir seus objetivos nas campanhas e, assim, conquistar a legitimidade moral por meio de processos.

A conquista da legitimidade pragmática, em um primeiro momento, e posteriormente da legitimidade moral, deu à Gazeta do Povo algo bastante perigoso em um processo de legitimação: conforto. Em paz com seus públicos e em constante crescimento, o jornal passou pelas décadas de 70 e 80 como o mais lido do Paraná e com a sensação de dever cumprido com seus leitores. No entanto, mais uma vez o ambiente mudou - só que, dessa vez, seus gestores não ampliaram seu contexto de referência. A Gazeta continuava sendo um jornal regional, quando o que se exigia dos jornais modernos era uma visão nacional e até mesmo internacional. $O$ avanço da tecnologia e a redemocratização foram cruciais para esse descompasso. Percebendo que sua legitimidade estava ameaçada, a Gazeta investiu numa resposta estratégica bastante utilizada por organizações, especialmente quando o principal objetivo é reparar sua legitimidade, que foi a aquiescência por meio do mimetismo. Vendo o que os grandes jornais do Brasil e do mundo já haviam feito para se modernizar, a Gazeta do Povo contratou uma consultoria estrangeira, de Navarra, atitude que DiMaggio e Powell (1983) chamaram de "busca de legitimidade a partir de critérios externos de valor". Apesar de a Gazeta do Povo manifestar uma lógica estratégica mimética, essa atitude foi fundamental tanto para ampliar o contexto de referência institucional (de regional para nacional/internacional) como serviu de plataforma para a emergência de uma nova identidade organizacional.

Assim, a entrada nos anos 2000 com uma nova forma de fazer jornalismo foi fundamental para o que viria a acontecer alguns anos depois. A década seria marcada por resposta estratégicas de desafio, tanto em relação ao governo, como em relação à própria maneira como o jornal era visto pela população. Até 2002, ano de eleição de Roberto Requião, a Gazeta ainda lutava para consolidar o modelo de Navarra e para reparar sua legitimidade um tanto quanto arranhada na década de 90 . O jornal era visto como um veículo que não se posicionava; os mais críticos o caracterizavam como "chapa branca" ou "em cima do muro". A resposta a esse ambiente veio com uma oposição inédita ao governo eleito, o que propiciou ao veículo reparar de forma mais ampla sua legitimidade, ao violar as fontes de pressões institucionais. A partir desse momento, seus públicos 
passaram a ver a organização como valiosa e digna de apoio porque suas características estruturais estavam de acordo com uma categoria moral, em um evidente processo de legitimação estrutural (SUCHMAN, 1995).

A publicação da Série Diários Secretos, quatro anos depois do fim do governo Requião, coroou a mudança de visão que o público tinha da Gazeta do Povo, por isso o episódio é indicado, neste trabalho, como o surgimento de uma nova identidade. Mantendo a perspectiva de desafio como resposta ao ambiente, agora o "ataque" final era ao seu próprio público leitor. A cartada derradeira, no fim da década de 2000, mostrou uma Gazeta do Povo mais comprometida e atenta ao ambiente em que estava inserida, até mesmo preocupada com o serviço público que um jornal normalmente deve prestar à população a que serve. A investigação de uma casa legislativa demorou para ser algo comum no jornalismo brasileiro, especialmente no paranaense, durante anos tão atrelado ao lado oficial da história. Como consequência, ouso afirmar que a Gazeta do Povo adquiriu nos últimos dois anos a legitimidade mais difícil de ser conquistada: a cognitiva, quando não predominam a avaliação da organização ou o interesse por ela, mas sim a cognição, a capacidade do público de considerá-la indispensável (SUCHMAN, 1995). Dessa forma, o jornal vem mantendo sua legitimidade, o que deve ser visto com bastante ressalva, já que a posição confortável é sempre uma ameaça à continuidade de uma organização.

O mais importante, diante dessa discussão, é entender que as respostas estratégicas dadas ao ambiente institucional podem ser sistematizadas como um processo, já que cada uma delas foi importante para entender como a Gazeta do Povo mudou sua imagem, conquistou e perdeu leitores, aumentou seus índices quanto aos atributos de imagem determinados. Nos momentos em que aquiesceu, respondeu com cautela a pressões institucionais surgidas em um ambiente ainda não tão claro e definido, em uma sociedade em constante mutação. Nos momentos em que atacou, sabia exatamente que tipo de legitimidade queria conquistar. Além disso, essa atitude também mostra que estratégias, como as de desafio, podem emergir e ser reforçadas na dinâmica de ação social, evidenciando que essas ações são coletivamente construídas.

Foi possível corroborar o que propõe Oliver (1991) em relação às respostas estratégicas, mas também comprovou que essas respostas, quando confrontadas com um ambiente e suas pressões, não são estáticas, tampouco únicas, já que a Gazeta do Povo, 
muitas vezes, mesclou algumas estratégias. Essas respostas, portanto, podem ser analisadas sob uma perspectiva temporal, a qual não só favorece como até mesmo condiciona o estudo da dinâmica de legitimação. O principal foi entender que elas podem mudar de acordo com alterações do ambiente e da própria organização, comprovando que o ambiente pode moldá-la e vice-versa. O estudo contribui para evidenciar que essa lógica de respostas é extremamente mutável e dinâmica, assim como o próprio processo de legitimação das organizações.

Uma última e importante constatação é que, para entender um processo de dinâmica de legitimação, é essencial não só considerar os ambientes técnico e institucional, mas especialmente olhar para o contexto institucional de referência, inerente aos gestores, ou seja, às pessoas. E essa perspectiva é, sob o ponto de vista da pesquisadora, a maior contribuição para entender que organizações sempre serão feitas por seres humanos. Olhar para as pessoas é olhar para o passado, o presente e o futuro de uma organização. Todos os períodos determinados nesta pesquisa como relevantes para a dinâmica de legitimação da Gazeta do Povo foram construídos por pessoas: fundadores, novos donos, consultores, governantes, jornalistas. Sem o componente humano, não há inovação técnica que permita um processo de desenvolvimento e de conquista de legitimidade. Para a pesquisadora, essa é a maior lição aprendida com a dinâmica de legitimação do jornal paranaense Gazeta do Povo.

\section{Referências}

BABIN; Barry; HAIR, Joseph; MONEY, Arthur; SAMOUEL, Phillip. Fundamentos de métodos de pesquisa em Administração. Porto Alegre: Bookman, 2003.

BERGER, Peter L.; LUCKMAN, Thomas. A construção social da realidade. Petrópolis: Vozes, 2002.

CHIARINI, Adriana Barreto. Como os diários impressos podem continuar interessantes com a concorrência dos serviços em tempo real? As reformas de O Globo em 1995 e do Correio Braziliense em 2000 à procura de resposta. Dissertação de mestrado - UnB. Brasília, 2000.

COMUNICAÇÃO. PMDB de Requião ataca jornal paranaense. Disponível em http://www.coletiva.net/site/noticia_detalhe.php?idNoticia=14044. Acesso em 20 jan 2012.

CRESWELL, J. Projeto de pesquisa: métodos qualitativo, quantitativo e misto. $2^{\mathrm{a}}$ edição. Porto Alegre: Bookman, 2007. 
CRUBELATTE, João Marcelo. Parâmetros de qualidade de ensino superior: análise institucional em IES privadas do Estado de São Paulo. Tese de doutorado - FGV. São Paulo, 2004.

CRUBELATTE, João Marcelo; MACHADO-DA-SILVA, Clóvis L. Mudança ambiental e adaptação organizacional: estudo comparativo de casos departamentais na UEM. Revista Organizações \& Sociedade. V. 5, nº 13, set/dez 1998.

DEFLEUR, M. L. e ROKEACH, S. B. Teorias da Comunicação de Massa. 5. ed. Rio de Janeiro: Jorge Zahar, 1993.

DI MAGGIO, Paul J.; POWELL, Walter W. The iron cage revisited: institutional isomorphism and collective rationality in organizational fields. American Sociological Review, Vol. 48, n 2, 1983.

DINES, Alberto; VOGT, Carlos; MELLO, José Marques de (org.). A imprensa em questão. Campinas: Editora da Unicamp, 1997.

DOWLING, John; PFEFFER, Jeffrey. Organizational legitimacy: social values and organizational behavior. The Pacific Sociological Review, Vol. 18, n 1, 1975.

GAZETA DO POVO. Disponível em www.gazetadopovo.com.br.

ERBOLATO, Mário L. Técnicas de codificação em jornalismo. São Paulo: Ática, 1991.

FERNANDES, José Carlos; SANTOS, Marcio Renato dos. Todo dia nunca é igual: notícias que a vida contou em 90 anos de circulação da Gazeta do Povo. Curitiba: Gazeta do Povo, 2010.

GOLANT, Benjamin D.; SILLINCE, John A. A. The constitution of organizational legitimacy: a narrative perspective. Disponível em http://oss.sagepub.com/content/28/8/1149. Acesso em 5 jun 2011.

IBGE. Disponível em www.ibge.gov.br. Acesso em 3 mar 2012.

KARAM, Francisco José Castilhos. Os riscos à legitimidade do jornalismo. 26 out 2010. Disponível

http://www.observatoriodaimprensa.com.br/artigos.asp?cod=613IMQ002. Acesso em 20 fev 2012.

LUTZ, Cleyton Pereira. O surgimento da Gazeta do Povo Esportiva - a alteração no caderno de esportes da Gazeta do Povo de segunda-feira http://www.intercom.org.br/papers/regionais/sul2008/resumos/R10-0381-1.pdf. Acesso em 12 fev 2012.

MACHADO-DA-SILVA, Clóvis; FERNANDES, Bruno. Mudança ambiental e reorientação estratégica: estudo de caso em instituição bancária. Revista de Administração de Empresas, v. 38, nº. 4, out/dez 1998. 
MANZINI, Eduardo José. Entrevista semi-estruturada: análise de objetivos e de roteiros. Disponível em http://www.sepq.org.br/IIsipeq/anais/pdf/gt3/04.pdf. 2004. Acesso em 20 fev 2012.

MARCONDES FILHO, C. A saga dos cães perdidos. São Paulo: Hacker Editores, 2002.

MELLO, José Marques de. A opinião no jornalismo brasileiro. Petrópolis: Vozes, 2003.

MARSHALL, L. O jornalismo na era da publicidade. São Paulo: Summus, 2003.

MASSEY, Joseph Eric. Managing organizational legitimacy: communication strategies for organization in crisis. Disponível em http://job.sagepub.com/content/38/2/153. Acesso em 2 mai 2010.

MEDINA, C. A. Notícia: um produto à venda. São Paulo: Summus, 1988.

MEYER, John W.; ROWAN, Brian. Institutionalized organizations: formal structure as myth and ceremony. American Journal of Sociology, v. 83, $\mathrm{n}^{\circ}$ 2, 1977.

PENA, Felipe. O jornalismo literário como gênero e conceito. Disponível em http://www.uff.br/contracampo/index.php/revista/article/viewFile/349/152.

OLIVEIRA FILHA, Elza. Apontamentos sobre a história de dois jornais curitibanos: Gazeta do Povo e O Estado do Paraná. Disponível em http://apps.unibrasil.com.br/revista/index.php/comunicacao/article/viewFile/539/457. Acesso em 22 fev 2012.

OLIVER, Christine. Estrategic responses to institutional processes. The Academy of Management Review, Vol. 16, $\mathrm{n}^{\circ}$ 1, 1991.

PORTAL G1. Acesso à internet chegou a 66,3 milhões de brasileiros em dezembro de 2009. Disponível em http://g1.globo.com/Noticias/Tecnologia/0,,MUL1484777$\underline{6174,00-}$

ACESSO+A+INTERNET+CHEGOU+A+MILHOES+DE+BRASILEIROS+EM+DEZ EMBRO+DE.html. Acesso em 5 mar 2012.

Prêmio Esso de Jornalismo completa 56 anos de história. Disponível em http://www.premioesso.com.br/site/historia/index.aspx. Acesso em 20 fev 2012.

ROSSONI, Luciano. A dinâmica de relações no campo da pesquisa em organizações e estratégia no Brasil: uma análise institucional. Dissertação de mestrado - UFPR, 2006.

SÁ, Virgínio. A influência do ambiente institucional sobre a estrutura das organizações educativas: entre a aquiescência e a manipulação. In: V Congresso Português de Sociologia, $\quad$ Porto, 2009. Anais... Disponível em http://www.aps.pt/cms/docs_prv/docs/DPR4616d36fbbff9_1.pdf. Acesso em 20 jan 2012.

SCOTT, W. Richard. Institutions and organizations: ideas and interests. Thousand Oaks: Sage, 2001. 
SELZNICK, Philip. Foundations of the theory of organization. American Sociological Review, v. 13, n $1,1948$.

SEVERO, Ana Karla da Silveira; NETO, Antônio Fausto. Um olhar sobre três jornais paranaenses e suas relações de comunicação, consumo e práticas sociais. Disponível em http://www.revistas.univerciencia.org/index.php/anagrama/article/view/6721/6078.

Acesso em 23 fev 2012.

SODRÉ, N. W. A História da Imprensa no Brasil. Rio de Janeiro: Mauad, 1999.

SUCHMAN, Mark C. Managing legitimacy: strategic and institutional approaches. Academy of Management Review, v. 20, n 3, 1995.

WOITOWICZ, Karina Janz. Recortes do tempo na escrita do jornal Diário da Tarde: história e sociedade no cotidiano jornalístico da capital paranaense no início do século 20. In: I Encontro Nacional de Pesquisadores em Jornalismo, Brasília, 28 e 29 de novembro de 2003. Anais... SPBJor.

YIN, Robert. Estudo de caso. Porto Alegre: Bookman, 2005.

ZELDITCH, Morris. Processes of legitimation: recent developments and new directions. Social Psychology Quarterly, v. 64, n 1, 2001. 